\title{
Diversidade Sexual e de Gênero, Ruralidade, Interioridade e Etnicidade no Brasil: Ausências, Silenciamentos e... Exortações
}

\author{
Fabiano Gontijo 1 \\ Universidade Federal do Pará
}

\begin{abstract}
Igor Erick ${ }^{2}$
Universidade Federal do Oeste do Pará
\end{abstract}

Resumo: No Brasil, no âmbito das Ciências Humanas e, em particular, da Antropologia, apesar da consolidação dos campos de estudos sobre ruralidade, por um lado, e, por outro, sobre gênero e sexualidade, percebe-se que pouco foram tratados, em ambos os campos, os aspectos relacionados à experiência da diversidade sexual e de gênero nas zonas rurais brasileiras. O mesmo se observa em relação aos contextos interioranos, caboclos e ribeirinhos e às situações etnicamente diferenciadas, indígenas e quilombolas, sobretudo na Amazônia, apesar de os estudos sobre etnicidade e sobre povos e comunidades tradicionais terem uma certa (e longa) trajetória no Brasil. Trata-se aqui de propor uma reflexão na área de Antropologia sobre a persistência da (quase) inexistência de pesquisas no Brasil sobre essas temáticas.

Palavras-chave: estudos rurais, estudos de gênero e sexualidade, estudos étnicos, diversidade sexual.

\footnotetext{
${ }^{1}$ Doutor em Antropologia pela École des Hautes Études en Sciences Sociales, França. Professor de Antropologia, Programa de Pós-Graduação em Antropologia (PPGA), Instituto de Filosofia e Ciências Humanas (IFCH), Universidade Federal do Pará (UFPA). Bolsista de Produtividade em Pesquisa, CNPq.

${ }_{2}$ Bacharelando em Antropologia, Programa de Antropologia e Arqueologia (PAA), Instituto de Ciências Sociais (ICS), Universidade Federal do Oeste do Pará (UFOPA). Bolsista de Iniciação Científica, CNPq.
} 


\title{
Sexual and Gender Diversity, Rurality, Countryside Identity, and Ethnicity in Brazil: Gaps, Silencings, and... Exhortations
}

\begin{abstract}
In Brazil, in the Humanities and in particular in anthropology, although the fields of studies on rural social life on gender and sexuality are very consolidated, little has been issued related to sexual and gender diversity in rural areas. The same is true to many other contexts, like the countryside social reality, the communities of "caboclos" and of people living in the banks of the Amazon Basin rivers, and the ethnically differentiated situations, like indigenous or maroon ones, although much has been written about ethnicity and about Amazonian people in Brazil. We will propose here some reflections on the continuing absence of these themes in anthropological research in Brazil. diversity.

Keywords: rural studies, gender and sexual studies, ethnicity, sexual
\end{abstract}

\section{Diversidad Sexual y de Género, Ruralidad, Interior y Etnicidad en Brasil: Ausencias, Silencios y... Exhortaciones}

\begin{abstract}
Resumen: En Brasil, en las Humanidades y en particular en la Antropología, a pesar de que se encuentran consolidados los campos de los estudios sobre la vida social rural, por un lado, y, por otro, sobre género y sexualidad, es evidente que poco se ha escrito sobre los aspectos relacionados con la diversidad sexual y de género en eses campos de estudio. Lo mismo se puede decir de los contextos del interior del país, de las realidades de comunidades de "caboclos" y de "ribereños" de las orillas de los ríos amazónicos, de pueblos indígenas o de marrones, aunque mucho se haya escrito sobre etnicidad y pueblos y comunidades tradicionales en Brasil. Vamos a proponer aquí algunas reflexiones sobre la persistencia de las ausencias de esas temáticas en las investigaciones antropológicas en Brasil.

Palabras-clave: estudios rurales, estudios de género y sexualidad, estudios étnicos, diversidad sexual.
\end{abstract}


Até a década de 1970, os escassos estudos sobre (homo) sexualidade no Brasil, de maneira geral, poderiam ser agrupados em três áreas:

- na primeira, os poucos estudos realizados na área das ciências biomédicas (incluindo-se aí a psicologia e as áreas correlatas), caracterizando as práticas patológicas e as identidades ou pseudo-categorias ontológicas a elas atreladas;

- na segunda, os raros estudos realizados na grande área das ciências humanas (incluindo-se aí a filosofia), caracterizando as práticas normais e as identidades ou pseudo-categorias ontológicas a elas atreladas, com designações de sociabilidades anormais.

- enfim, na terceira, os textos na área de literatura (incluindo-se aí os ensaios jornalísticos realistas e naturalistas), com um número relativamente extenso de obras que abordavam direta ou indiretamente (nomeadamente ou não) as experiências sexuais muito diversas e bem particulares de setores da população brasileira e a relação dessas experiências com os modos de vida desses setores, seja como objeto principal da obra ou como elemento tangencial ao objeto principal, seja como fruto de uma reflexão moral (por exemplo, O Bom Crioulo, de Adolfo Caminha) ou como relato de vivências mundanas divergentes, estigmatizadas e periféricas (por exemplo, Capitães de Areia, de Jorge Amado).

Ao passo que os estudos médicos encaravam as sexualidades desviantes (ou seja, a homossexualidade) da ordem sexual então imposta (ou seja, da heteronormatividade) como problemas a serem corrigidos e tratados, as ciências humanas, por sua vez, as viam como curiosidades das camadas populares, geralmente negras, periféricas, umbandistas, prostituídas e regionais. A literatura, enfim, as viam como "fatos" e "experiências" a serem relatados, ainda que como subterfúgios ardilosos para a emissão de juízos morais (de cunho médico e/ou filosófico) ${ }^{3}$. Pouco - ou praticamente nada - foi versado sobre as experiências desviantes no universo rural, em contextos interioranos ou em situações etnicamente diferenciadas - como os que seriam comuns nas regiões Norte e Nordeste do Brasil e na Amazônia em geral...

Na década de 1930, Ruth Landes, a jovem antropóloga norte-americana que estava de passagem pela Bahia para estudar os "cultos de possessão afrobrasileiros", ficou surpresa diante das experiências homossexuais que observou nos terreiros visitados e escreveu o polêmico artigo intitulado "Matriarcado Cultural e Homossexualidade Masculina" (LANDES, 1967). Mais de trinta anos depois, era a vez de Peter Fry, um outro jovem antropólogo estrangeiro, deste vez inglês, se surpreender diante dos mesmos fatos, agora na cidade de Belém. Seguindo a pista de Ruth Landes, Fry realizou, em 1974, uma pesquisa de campo etnográfica que desembocaria na publicação do artigo intitulado "Homossexua-

3 Para as referências acerca da genealogia dos estudos sobre (homo)sexualidade no Brasil, ver o próprio artigo de Fry (1982b), mas também os de Arney, Fernandes e Green (2003) e ainda, para entender a maneira como a obra de Fry abriu novos espacos para a instituição do campo dos estudos sobre (homo)sexualidade no Brasil, sobre novas bases teóricas e metodológicas, ver também Facchini (2003) e Carrara e Simões (2007). Enfim, para o "estado da arte" mais atualizado dos estudos sobre gênero e sexualidade no Brasil, ver o dossiê "Antropologia, Gênero e Sexualidade no Brasil”, organizado por Piscitelli e publicado nos Cadernos Pagu, n. 42, 2014, em particular os artigos de Simões e Carrara (2014) e Moutinho (2014). 
lidade Masculina e Cultos Afro-Brasileiros", divulgado inicialmente em inglês sob a forma de comunicação apresentada em congresso (FRY, 1982a). Fry, realizando a investigação em locais de cultos de possessão na capital paraense, inferiu sobre a relação entre "homossexualidade e religiosidade", propondo um esboço do que chamaria, a partir daí, de "sistema de representação hierárquico da sexualidade masculina”, comum, segundo ele, em cidades do Norte e Nordeste brasileiros, assim como nas periferias dos grandes centros urbanos industrializados do Sul e do Sudeste e eventualmente nas zonas rurais.

A questão seria aprofundada por Fry em seu artigo intitulado "Da Hierarquia à Igualdade: a construção histórica da homossexualidade no Brasil" (1982b), onde o autor avançou que o estudo dos sistemas de representações sobre a sexualidade masculina contribuiria para o estudo da sociedade brasileira como um todo, já que os sistemas de representações seriam produzidos num contexto político. Analisando o "que as pessoas dizem que fazem e o que acham que deveria ser feito" no tocante à sexualidade (FRY, 1982b: 88 e 89), o autor identificou alguns modelos a partir da articulação entre sexo fisiológico ("atributos físicos que distinguem machos e fêmeas", p. 89), papel de gênero (referentes "ao comportamento, aos traços de personalidade e às expectativas sociais associadas normalmente ao papel masculino ou feminino”, pp. 90 e 91), comportamento sexual ("comportamento sexual esperado de uma determinada identidade”, p. 91, como atividade e passividade) e orientação sexual ("sexo fisiológico do objeto de desejo sexual”, p. 91, ou seja, homossexual, heterossexual ou bissexual).

Fry propôs então dois grandes modelos ou sistemas de classificação: por um lado, o modelo hierárquico, que dividiria o mundo em "homens" e "bichas" e, por outro, um modelo mais simétrico ou igualitário, que dividiria o mundo em "homossexuais", "heterossexuais" e "bissexuais". Enquanto o primeiro modelo encontrava sua origem na história colonial brasileira e seria, no momento da escrita do artigo, "bastante hegemônico nas classes mais baixas e no interior do país" (Ibidem: 93), o segundo modelo, por sua vez, seria oriundo do sistema médico-científico que produzia a "condição homossexual" e se alastrava pelas camadas médias dos grandes centros urbanos brasileiros, representando a modernidade e a vanguarda em termos comportamentais. Os movimentos políticos homossexuais nascentes nas décadas de 1970 e 1980 no Brasil se baseavam no segundo modelo, segundo Fry, o que estaria gerando, naquele momento, uma tensão (política) entre as tendências identitárias dos movimentos e as experiências homossexuais efetivas (mais próximas do modelo hierárquico).

Os escritos de Fry (1982a; 1982b), assim como os de Fry e MacRae (1982), e as obras de Guimarães (2004 [1977]), Parker (1986), Perlongher (1987), Mott (1987a; 1987b), Muniz de Oliveira (1992), Heilborn (1996; 2004 [1992]) e Costa (1992), dentre outras, geralmente com propostas de tipologias e mapeamentos, contribuíram decisivamente para a instituição do campo dos estudos sobre (homo)sexualidade no Brasil. Mas, quase sempre, (homo)sexualidade masculina, urbana, branca (ou negra urbana) e das regiões Sudeste ou Sul...

Desde as décadas de 1980/90, a diversidade sexual e de gênero vem se consolidando como um forte objeto de estudo (VANCE, 1995) nas mais diversas instituições de ensino e pesquisa nacionais, principalmente nas Ciências Humanas e Sociais. São abordados temas variados que vão desde as questões básicas acerca do que é ser homossexual e como se constituem as categorias de designação vinculadas às identidades, às identificações e à diversidade sexual e de gênero eventualmente decorrentes das práticas sexuais entre sujeitos considerados 
(ou que se consideram) como sendo do mesmo sexo/gênero e as formas de sociabilidades homossexuais, até questões mais particulares ou singulares acerca da literatura e das produções culturais homossexuais ou homocultura; do mercado e do consumo "gays" ou "mercado rosa"; da especificidade da saúde de mulheres homossexuais ou de sujeitos transexuais e do envolvimento no combate à epidemia de HIV/AIDS; do envelhecimento em homossexuais; da organização política de gays, lésbicas, travestis e transexuais; das tecnologias da transexualização, do sexo e do gênero; dos novos regimes morais; das experiências religiosas homossexuais; do preconceito, da discriminação e da homofobia; dos direitos e do acesso à cidadania; das conjugalidades, das parentalidades e dos arranjos familiais homossexuais; dentre tantos outros temas. No entanto, pouco ou nada se escreveu sobre esses e outros temas em contextos rurais e interioranos e/ou em situações etnicamente diferenciadas, sobretudo amazônicas.

Na sociedade brasileira contemporânea, assim, presencia-se uma efervescência de práticas (de pesquisa e de ativismo político) que questionam o padrão heteronormativo ou a heterossexualidade compulsória (RICH, 1983; BUTLER, 1990) enquanto poderoso sistema ideológico ou sistema cultural, a partir de sujeitos lésbicas, gays, bissexuais, travestis, transexuais e intersexuais, com todas as peculiaridades que o contexto sociocultural e histórico compõe. Motivado por e motivando esse fenômeno, os movimentos sociais vinculados aos direitos sexuais e os intelectuais afeitos à temática colocam cada vez mais questões visando desestabilizar a normatização de condutas que encerram essas experiências e, logo, interpelar a "analítica da normalização" (MISKOLCI, 2009), ou seja, a forma como as fronteiras da diferença são constituídas ou a maneira como se dá a construção de padrões que regulam a vida dos sujeitos em suas práticas cotidianas.

Se considerarmos o gênero, junto com Butler (2003), como um sistema de regras, convenções, normas sociais e práticas institucionais que produzem performativamente os sujeitos que pretende descrever, percebemos que não se tem ou é um certo gênero - masculino ou feminino -, mas trata-se de um conjunto de atos que são repetidos no interior de uma matriz heteronormativa. Performativamente, os indivíduos se tornam sujeitos porque "sujeitados", por meio de formações discursivas (FOUCAULT, 1984), a esse aparato de poder representado pela heteronormatividade (BUTLER, 2003). Institui-se, segundo Butler, a continuidade entre sexo/gênero/prática sexual/desejo, o que implica na afirmação de que o desejo e a prática sexual decorrem naturalmente do gênero e do sexo. Ainda segundo Butler, a construção dessa continuidade ou coerência oculta às descontinuidades presentes tanto em contextos heterossexuais quanto nos homossexuais. O poder, ao circular, entrelaça os sujeitos em múltiplas e complexas relações, operando na classificação e imposição de normas, dentre as quais a que cria o efeito de continuidade entre sexo/gênero/prática sexual/desejo. Para Butler, recorrendo a Foucault, essa continuidade não é algo evidente, mas se torna uma categoria normativa, um ideal regulatório. Isso quer dizer que não é algo natural e estático, mas existiria, portanto, "um processo pelo qual as normas regulatórias materializam o 'sexo' e produzem essa materialização através de uma reiteração forçada destas normas” (BUTLER, 2001: 154). A materialização não é dada, mas construída e, por essa razão, as normas precisam ser constantemente reiteradas. Os corpos nunca se conformam totalmente a essa materialização imposta e é precisamente isso o que vem sendo um interessante objeto de estudo de uma Antropologia da sexualidade nos dias de hoje (FAUSTO-STERLING, 2000). 
Questionar e interpelar a heteronormatividade levaram às "teorias queer" ou aos "estudos queer", que têm na interseccionalidade um de seus preceitos teóricos e metodológicos (JAGOSE, 1996; PISCITELLI, 2008, 2012). Vem se configurando uma proposta de estudo em que o gênero e a sexualidade continuam importantes para analisarmos experiências de sujeitos que fogem da norma heterossexual, mas que aponta para outros marcadores sociais da diferença que também devem ser levados em consideração para que se possa entender como diferentes formas de opressão se relacionam de forma igualitária, e não mais hierarquizante. Refletir sobre como as experiências generificadas, racializadas, etnicizadas, geracionais, sexuais, religiosas e regionais tomam formas próprias que não podem ser analisadas de forma autônoma do contexto nacional e global de diferenciação, de desigualdade e de "normalização" (FOUCAULT, 1988) em que se inserem, eis o desafio que nos colocamos para tratar da diversidade sexual e de gênero em contextos rurais ou interioranos e em situações etnicamente diferenciadas nas regiões Norte, Nordeste e, em geral, na Amazônia.

Considera-se aqui, junto com Teresa de Lauretis, que "Os termos para uma construção diferente do gênero também existem, nas margens dos discursos hegemônicos. Propostos de fora do contrato heterossexual, e inscritos em práticas micropolíticas, tais termos podem também contribuir para a construção do gênero [...]." (LAURETIS, 1994: 228). Seus efeitos ocorrem ao nível local de resistências, na subjetividade e na auto-representação. É precisamente esse "nível local de resistências" que parecia pouco ou nada estudado pela Antropologia no Brasil no âmbito mesmo dos estudos de gênero e sexualidade para além dos estudos sobre as experiências homossexuais em contextos urbanos das regiões Sudeste e Sul, e que vem, recentemente, sendo abordado, na tentativa de refletir sobre as particularidades locais e regionais brasileiras, tanto da construção dos discursos hegemônicos e sua manutenção, quanto dos deslocamentos singulares das fronteiras desses discursos.

Em 2006, uma tese de doutorado e uma dissertação de mestrado em Antropologia, defendidas respectivamente na Universidade de São Paulo e na Universidade de Brasília, trataram, com abordagens diferentes, de aspectos relativos à temática da sexualidade no mundo rural brasileiro, acrescentando, assim, novidades aos já tão consolidados estudos rurais brasileiros, por um lado, e, por outro, aos também já tão consolidados estudos sobre gênero e sexualidade no Brasil, inclusive na perspectiva "queer".

A tese de Silvana de Souza Nascimento e a dissertação de Paulo Rogers Ferreira partiram da denúncia da (quase total) ausência de pesquisas sobre sexualidade no âmbito dos estudos rurais4. A tese de Nascimento, intitulada "Faculdades Femininas e Saberes Rurais. Uma Etnografia sobre Gênero e Sociabilidade no Interior de Goiás", tratou das relações de gênero no mundo rural levando-se em consideração a experiência da vivência das sexualidades, ao passo que a dissertação de Ferreira, intitulada "Os Afectos Mal-Ditos: o indizível das sociedades camponesas", tratou mais especificamente da experiência das sexualidades no interior do Ceará.

Antes, na década de 1990, artigos de Ellen e Klaas Woortmann (1993, dentre outros) já haviam atentado para algumas particularidades da sexualidade no

4 Entende-se por estudos rurais o conjunto de textos oriundos de pesquisas realizadas no contexto das ruralidades ou do mundo rural e que se servem de um aparato teórico-metodológico das ciências sociais e humanas. Maria José Carneiro fala de ruralidades, no plural, como representações sociais que orientam “(...) práticas sociais distintas em universos culturais heterogêneos, num processo de integração plural com a economia e a sociedade urbano-industrial.” (1998, p. 12) ou "como um processo dinâmico em constante reestruturação dos elementos da cultura local, mediante a incorporação de novos valores, hábitos e técnicas" (2008: 35). 
mundo rural, embora esse não fosse o foco dos estudos. Depois, a dissertação de mestrado de Luanna Mirella, intitulada "Localidade ou Metrópole? Demonstrando a capacidade de atuação política das travestis no mundo-comunidade", defendida em 2010 junto ao Programa de Pós-Graduação em Antropologia Social da Universidade de Brasília, apresentou a trajetória biográfica de Kátia Tapety, travesti que exerceu cargos políticos em um pequeno município rural piauiense, mas não se tratou especificamente de uma pesquisa sobre a sexualidade de travestis no mundo rural brasileiro. Mais recentemente, as pesquisas realizadas por Martinho Tota (2012, 2013) e por Roberto Marques (2012, 2014), ambos no Nordeste, vêm abordando com primor a sexualidade divergente em contextos interioranos - seja entre indígenas, como Tota junto aos potiguar, seja em festas de forró eletrônico, como Marques. Vale ressaltar ainda as pesquisas recentes de Moisés Lopes (2014), na capital mato-grossense, junto a militantes e ativistas dos direitos de gays, lésbicas, bissexuais, travestis, transexuais e transgêneros, e as pesquisas de Guilherme Passamani (2015) na região pantaneira de Corumbá, Mato Grosso do Sul, junto a idosos homossexuais interioranos.

Alguns desses trabalhos, assim como alguns artigos que Nascimento vem publicando nos últimos anos sobre as experiências da diversidade sexual e de gênero consideradas como desviantes em contextos rurais e interioranos da $\mathrm{Pa}$ raíba (NASCIMENTO, 2014) serviram de inspiração inicial para nossas indagações sobre a experiência das sexualidades no mundo rural piauiense, num primeiro momento, e, em seguida, no interior do Pará (e, agora, na Pan-Amazônia de forma geral).

Na pesquisa bibliográfica desenvolvida durante o estágio pós-doutoral, realizado no âmbito das atividades relativas à vigência de um convênio do tipo PROCAD firmado entre o Programa de Pós-Graduação em Antropologia e Arqueologia (PPGAArq) da Universidade Federal do Piauí (UFPI) e o Programa de Pós-Graduação de Ciências Sociais em Desenvolvimento, Agricultura e Sociedade (CPDA) da Universidade Federal Rural do Rio de Janeiro (UFRRJ)5, foi feita uma análise dos artigos e dossiês em periódicos especializados e das publicações que reúnem textos com o "estado da arte" sobre os temas da ruralidade e do gênero e da sexualidade nas Ciências Sociais confirmando as inúmeras lacunas e quase total ausência dos relatos sobre a vivência sexual e das experiências da sexualidade dos camponeses ${ }^{6}$, não somente nos estudos rurais - como Nascimento (2006) e Ferreira (2006) já haviam notado -, mas também nos estudos de gênero e sexualidade7.

Após algumas viagens ao interior do Piauí (regiões Centro-Sul e Norte do estado) para conversar com sujeitos cujas trajetórias e experiências não se encaixavam exatamente naquilo que se vinha lendo, por um lado, sobre aquele

5 O estágio de pós-doutorado aconteceu entre outubro de 2012 e fevereiro de 2013, no CPDA/UFRRJ, sob a supervisão da Profa. Eli de Fátima Napoleão de Lima. A pesquisa bibliográfica, no entanto, prosseguiu após o estágio, incluindo também a metade do ano de 2014.

${ }_{6}$ Cabe aqui um esclarecimento sobre o uso que fazemos da categoria camponês. Sem entrar no acalorado debate sobre definições, entendemos o camponês como o sujeito "múltiplo" que vive nas zonas rurais (ainda que, muitas vezes, a zona rural não seja definida pelos próprios sujeitos que ali e/ou dela vivem, mas por instâncias administrativas e governamentais ou não-governamentais). Esse sujeito é múltiplo, pois sua construção identitária não pode mais ser reduzida a uma ou duas de suas atividades, geralmente entendida/s como econômica/s. A partir de Kearney (1996) - e também Brunt (1992) -, falarei de camponês (e não de "polybian") como um sujeito vinculado a múltiplos processos sociais, estratégias econômicas, dinâmicas de poder e, enfim, lógicas de diferenciação cultural que marcam sua presença no mundo - é assim que os sujeitos que encontramos no interior do Piaú e temos encontrado no interior do Pará e na Amazônia em geral se mostravam e parecem se mostrar.

7 Por estudos de gênero e sexualidade, entende-se aqui o conjunto de textos oriundos de pesquisas realizadas em contextos sociológicos e antropológicos diversos, retratando a construção social e a formulação cultural não somente das relações e estruturas de gênero (ROSALDO et alii, 1979; SCOTT, 1995; BUTLER, 2003), mas também das diferenças sexuais (VANCE, 1995; HEILBORN, 1999; CARRARA \& SIMÕES, 2007; SIMÕES \& CARRARA, 2014; MOUTINHO, 2014) 
camponês tal qual tratado pelos estudos rurais, e, por outro lado, sobre identidades e transgressões sexuais e de gênero nos estudos de gênero e sexualidade, decidiu-se indagar-se sobre o porquê (e o como) desses desencaixes ou lacunas, ausências e possíveis silenciamentos.

A inserção no contexto amazônico levou-nos a acrescentar a essa preocupação aquela com os desencaixes, lacunas, ausências e possíveis silenciamentos verificados também no que diz respeito à experiência da diversidade sexual e de gênero em contextos etnicamente diferenciados e em pequenas e médias cidades amazônicas, nos "interiores", onde as categorias do rural utilizadas para o entendimento das realidades específicas das regiões Sul e Sudeste parecem não ter o mesmo vigor diante da entrada em cena de categorias como "caboclo", "ribeirinho" e "homem amazônico" (WAGLEY, 1974; MILLER, 1977; PARKER, 1985; MOTTA-MAUÉS, 1989; CHIBNIK, 1994; LIMA-AYRES, 1999; HARRIS, 1998; RODRIGUES, 2006), tornando a realidade ainda mais complexa. Essa complexidade tem nos levado à proposta, ainda que tímida, da noção de "interioridade": um espaço-tempo que transita entre ruralidade e urbanidade, confundido pela dinâmica da etnicidade, em contexto amazônico, nas figuras do cabloco e do ribeirinho, além do indígena e do quilombola.

Algumas importantes referências sobre o assunto das experiências da diversidade sexual e de gênero nos contextos interioranos e nas situações etnicamente diferenciadas foram encontradas até agora em nossas buscas bibliográficas. Para os estudos sobre sexualidades entre povos indígenas, parece fundamental o artigo de Cristina Donza Cancela, Flávio Leonel da Silveira e Almires Machado (este último, indígena Guarani do Mato Grosso do Sul), intitulado "Caminhos de uma Pesquisa acerca da Sexualidade em Aldeias Indígenas no Mato Grosso do Sul”, publicado na Revista de Antropologia (USP), no número 53, volume 1, em 2010, pp. 199-235, abordando a maneira como os pesquisadores e o indígena construíram um diálogo sobre a possibilidade de existência das práticas sexuais entre pessoas consideradas como sendo do mesmo sexo nas aldeias da etnia de origem de Almires.

A coletânea intitulada Gênero e Povos Indígenas, organizada por Ângela Sacchi e Márcia Maria Gramkow, publicada no Rio de Janeiro e em Brasília pelo Museu do Índio e pela Funai, em 2012, traz textos que também contribuem para instigar a discussão sobre o assunto, mas que pouco problematizam a diversidade sexual e de gênero nas situações objetivas abordadas.

O número 41, de 2013, do periódico Cadernos Pagu, da Universidade de Campinas, trouxe uma grande contribuição para os estudos sobre gênero e sexualidades em contextos indígenas, em particular com os artigos de Vanessa R. Lea ("O Som do Silêncio (Paul Simon)", pp. 87-93, onde a autora aborda o fato de que "a necessidade de acomodar-se ao mundo não-indígena atiça a curiosidade dos povos indígenas a respeito da sociedade envolvente", em particular no que diz respeito ao interesse de indígenas pela pornografia e as fontes de erotismo dos não-indígenas) e Cecília MacCallum ("Notas sobre as categorias 'gênero' e 'sexualidade' e povos indígenas", pp. 53-61, que trata da fragilidade do uso das categorias de gênero e sexualidade para tratar de realidades indígenas) - embora pouco se tenha falado de práticas sexuais entre pessoas consideradas como sendo do mesmo sexo nas situações concretas analisadas pelos autores.

O trabalho de Estêvão Fernandes $(2014,2015)$ sobre "homossexualidade indígena no Brasil" - eis a maneira como o autor define seu campo de estudo -, trata do que ele afirma não ter encontrado na literatura, apesar das diversas referências a sexualidades indígenas em alguns textos já considerados clássicos, 
como em Charles Wagley, Pierre Clastres, Claude Lévi-Strauss, Alfred Métraux, Darcy Ribeiro, dentre outros, por um lado, e, por outro, em alguns textos da historiografia também clássica sobre os nativos americanos nos primeiros momentos dos contatos com os europeus.

Enfim, um seminário organizado por Luisa Elvira Belaunde (MN/UFRJ), Els Lagrou (IFCS/UFRJ) e Marina Vanzolini ((PPGAS/USP), realizado no Instituto de Filosofia e Ciências Sociais da Universidade Federal do Rio de Janeiro, em junho de 2015, tinha por objetivo discutir a sexualidade indígena - com o instigante título de "Foucault na Amazônia? Sexualidades Indígenas" -, abrindo uma nova arena para a discussão do assunto, assim como o Forum Temático "Diversidade Sexual e de Gênero: Interseccionalidade, Violência e Regionalidade" (do qual fizemos parte), coordenado por Júlio Simões, na V Reunião Equatorial de Antropologia, realizada em Maceió, em julho de 2015.

Assim, concluem-se as pesquisas bibliográficas realizadas até o momento percebendo que, no que diz respeito aos estudos rurais, parece que a maior parte dos artigos e textos analisados estão ora voltados para a organização social vinculada aos aspectos econômicos da vida no campo, ora voltados para as questões morais relativas à família e aos arranjos familiares camponeses - o gênero aparece quase sempre na forma da mulher trabalhadora e/ou militante ou dos papéis familiares.

No que diz respeito aos estudos de gênero e sexualidade, quando há articulação com a ruralidade, nota-se um grande número de artigos e textos que abordam, num primeiro momento, a condição da mulher camponesa (reprodutora $\mathrm{e}$ eventualmente produtora), às vezes vinculada aos movimentos sociais no campo, e/ou, em seguida, as relações de poder que permeiam as relações de gênero e as transformações dessas relações no mundo rural contemporâneo. A sexualidade (a)parece relegada à vida urbana como um "indizível das sociedades camponesas", para parafrasear Ferreira (2006). ${ }^{8}$

A sexualidade e, mais particularmente, a diversidade sexual e de gênero e as práticas sexuais que podem se tornar marcadores sociais da diferença interseccionalizados nas pesquisas sobre o mundo rural ou na etnologia indígena ou nos estudos de realidades quilombolas, caboclas e ribeirinhas não teriam se transformado em objetos de estudo per se por diversas razões, não necessariamente por uma suposta incapacidade dos pesquisadores em perceber sua importância para a compreensão das relações sociais marcadas pelas ruralidades, pela etnicidade ou pela regionalidade. Talvez a principal dessas razões seja a própria agenda de pesquisas, tanto nos estudos rurais ou nos estudos étnicos ou sobre realidades interioranas, como nos estudos de gênero e sexualidade, pautada por outros interesses de pesquisa ligados a certas tradições intelectuais (muitas vezes, a montagem da agenda se faz de acordo com demandas oriundas dos mais diversos pontos do campo de força em jogo nas Ciências Sociais) - no caso dos estudos rurais, em algumas tradições intelectuais que buscam entender as sociedades camponesas como sistemas sociais específicos, a economia e a política se tornam dimensões mais privilegiadas do que a sexualidade, entendida, esta última, como secundária (pensamos aqui, como exemplo, numa certa

${ }^{8}$ Nos estudos rurais, a invisibilização do outro no que diz respeito às práticas sexuais e às construções identitárias ligadas a essas práticas parece concernir também à criança e até mesmo, em menor grau, ao negro, o que é confirmado, não somente pelos trabalhos de Ferreira (2006, 2008) e Nascimento (2006, 2012), como apontamos acima, mas também pelo textos de Maria Isabel Ferraz Pereira Leite (1996) e, mais recentemente, de Jairo Barduni Filho, Ana Louise de Carvalho Fiúza, Erika Oliveira Amorim e Adriana Maria da Silva Costa (FILHO et al., 2010). 
tradição já clássica desenvolvida, por um lado, por Eric Wolf e Sydney Mintz, e, por outro, por Henri Mendras).

No caso da etnologia indígena, Fernandes apontou, em sua tese recémdefendida em outubro de 2015, para as consequências ético-políticas envolvidas no reconhecimento da existência da prática não ritual da diversidade sexual em contextos indígenas brasileiros (FERNANDES, 2015). Em outras realidades indígenas latino-americanos ou norte-americanos, parece haver uma certa tradição de estudos sobre a sexualidade (HURTADO, 2014). Ouvimos da plateia, num evento em que foram apresentados alguns resultados parciais dessas reflexões (II Colóquio de Antropologia da UFMT, em Cuiabá, realizado em outubro de 2015), que não se fala tanto de sexualidade indígena porque esse não é um tema considerado como relevante pelos indígenas - em termos, por exemplo, cosmológicos - para ser enfatizado no momento de uma pesquisa, mas isso não parece ser verdadeiro para a totalidade das etnias indígenas brasileiras, como se conclui da própria programação do seminário realizado em junho de 2015 no IFCS/UFRJ, já citado acima.

Embora historicamente as Ciências Humanas e, em particular, as Ciências Sociais e a Antropologia, venham deixando de lado esses aspectos da vida social no meio rural e interiorano ou em situações etnicamente diferenciadas problematizados aqui, percebe-se que, também historicamente, outros campos de produção de saberes e conhecimentos, como a literatura brasileira consagrada ou as artes plásticas celebradas, estão repletos de referências (muitas vezes explícitas) à sexualidade do camponês ou do homem que vive no campo, do indígena ou do africano do interior do país, do caboclo e do ribeirinho amazônida e do interiorano em geral. Para citar somente um caso emblemático da literatura brasileira, pensemos na relação dos personagens Diadorim e Riobaldo, de Grande Sertão: Veredas, de 1956, de autoria de Guimarães Rosa ${ }^{9}$. E, nas artes plásticas, não passa despercebida a sensualidade e a sexualidade de alguns personagens rurais e/ou etnicamente marcados de Cândido Portinari ou até mesmo de Djanira.

No entanto, é sabido que as Ciências Humanas se constituíram, enquanto ciências, como legítimas provedoras de "verdades" sobre o mundo, por oposição à literatura, esta relegada ao campo da "ficção" e, eventualmente, da produção de informação despreocupada com as "verdades", como já era apontado pela crítica pós-moderna (CLIFFORD, 1998; CLIFFORD \& MARCUS, 2010). Coube às ciências, assim, a instituição do que seria bon à penser; e, à literatura e às artes plásticas, o "resto", a saber a sexualidade no mundo rural ou nos contextos interioranos e situações etnicamente diferenciadas, dentre outros temas.

Tratou-se, então, em nossas pesquisas - assim como naquelas de Fernandes $(2014 ; 2015)$ ou nas de Tota $(2012 ; 2014)$-, de refletir, a partir de uma perspectiva desconstrutivista atenta aos efeitos da "analítica da normalização" (MISKOLCI, 2003), ao modus operandi dos biopoderes (FOUCAULT, 1988) e das tecnologias de gênero (LAURETIS, 1994), sobre as trajetórias e experiências de sujeitos nada conformes àquelas que encontramos comumente nos livros de histórias sobre eles, sobre seus territórios, sua economia, sua organização social e suas relações de parentesco, sua mobilização política, sua moralidade, sua religiosidade, seus ritos e mitos... em que nunca são levados em conta seus corpos

9 Nas Ciências Humanas e Sociais brasileiras em sua formação, encontramos referências à experiência sexual dos sujeitos que vivem no interior do Brasil na obra majestosa de Gilberto Freyre, por exemplo, e até mesmo nas obras de Caio Prado Júnior, Sérgio Buarque de Holanda, Paulo Prado ou Antônio Cândido, obras muitas vezes consideradas ensaísticas. 
desejantes e desejados ou seus "afectos mal-ditos" (FERREIRA, 2006), como se esses sujeitos "só” reduzissem sua existência à reprodução de suas tradições.

Ferreira (2008) aponta para o fato de que há uma ideologia (ou discursividade) que faz com que o sujeito rural brasileiro - e, por extensão, os sujeitos interioranos e etnicamente diferenciados -, ao nascer, já possua funções prédeterminadas, dentre elas as de crescer, multiplicar e se sustentar com o suor do seu próprio rosto, condenando-se, assim, tudo que não esteja diretamente ligado ao seu trabalho, inclusive os desejos que são inerentes a este sujeito. $\mathrm{O}$ autor fala de sexualidades silenciadas, esquecidas ou não ditas, em nome de uma "ruralidade idealizada": o camponês é percebido como o indivíduo que trabalha para manter a sua prole numa relação em que não há lugar para práticas sexuais que não tenham como finalidade a procriação, estando a busca pelo deleite condenada às "moitas" e aos "indizíveis" disseminados pelos ruídos.

Os estudos rurais, assim como os estudos sobre realidades interioranas, contextos indígenas e etnicamente diferenciados, deixaram de lado (ou abordaram tangencialmente), durante muito tempo, essas temáticas consideradas periféricas, por um lado, por não tratarem da relação do camponês ou interiorano com sua produção, privilegiando-se, assim, os estudos sobre economia doméstica, conflitos agrários, sindicatos rurais, migrações, dentre outros - isso se deve, talvez, à contaminação dos estudos rurais pelos ideais desenvolvimentistas e heteronormativos... ou, por outro lado, simplesmente, porque essas temáticas não faziam parte da agenda de pesquisas naqueles momentos; ou, enfim, por não considerarem relevantes os discursos sobre a sexualidade proferidos por indígenas e quilombolas para o entendimento das cosmologias locais.

Quando despontam sujeitos que vivenciam o seu direito à liberdade de escolha e que destoam dos sujeitos com comportamentos "funcionais", tidos como "padrão", são logo taxados de "desviantes" (VELHO, 1985). Assim, no que diz respeito à diversidade sexual e de gênero, os mundos rural e interiorano amazônicos e os contextos indígenas e etnicamente diferenciados estariam apresentando uma ruptura com uma forte discursividade, aquela referente à longa tradição heteronormativa? Ou as relações observadas nos mundos rural e interiorano amazônicos e em contextos indígenas e etnicamente diferenciados seriam simplesmente o retrato - agora em cores - de uma realidade complexa e diversificada, muitas vezes negada pelos estudiosos dessas realidades e contextos? Ou o que vemos diz respeito simplesmente à dinâmica mesmo da vida social como um todo, em qualquer contexto?

Nossas pesquisas em andamento podem servir assim para exortar para que se reconheçam as complexas e dinâmicas interações desses sujeitos rurais, interioranos, indígenas e/ou quilombolas, caboclos e ribeirinhos e sua maneira criativa de constituir relações afetivas, através de suas narrativas biográficas (BAUMAN, 1986; PENEFF, 1990; FEAL, 1990; GONÇALVES, 2012), voltandose assim para a maneira como os "padrões hegemônicos de normalidade" (BUTLER, 2003) seriam (re)interpretados e experimentados (talvez às avessas) em contextos culturais distintos, criando novos ou outros sujeitos imbuídos de novas ou outras moralidades e (até mesmo) constituindo novas ou outras legalidades. 
ARNEY, Lance, FERNANDES, Marise \& GREEN, James. Homossexualidade no Brasil: uma bibliografia anotada. Cadernos AEL, v. 10, n. 18/19, 2003, p. 317348.

BARDUNI FILHO, Jairo; FIÚZA, Ana Louise de Carvalho; AMORIM, Erika Oliveira; COSTA, Adriana Maria da Silva. A Transformação das Relações Afetivas no Meio Rural: breves anotações das relações oficiosas, e oficiais na perspectiva de gênero. Anais do VIII Congreso Latinoamericano de Sociología Rural (ALASRU), Porto de Galinhas, 2010, pp. não informadas Disponível em: < http://www.gerar.ufv.br/publicacoes/A_TRANSFORMACAO_DAS_RELACOE S_\%2OAFETIVAS_NO_MEIO_RURAL_BREVES_ANOTACOES_DAS_RELAC OES_OFICIOSAS_E_OF.pdf >. Acesso em: 4 de abril de 2013.

BAUMAN, R. Story, Performance, and Event: contextual studies of oral narrative. Cambridge: Cambridge University Press, 1986.

BRUNT, D. Mastering the Struggle: gender, actors and agrarian change in a mexican ejido. Amsterdam: CEDLA, 1992.

BUTLER, Judith. Problemas de Gênero: feminismo e subversão da identidade. Rio de Janeiro: Civilização Brasileira, 2003.

CANCELA, Cristina D., SILVEIRA, Flávio L. A. e MACHADO, Almires. Caminhos de uma Pesquisa acerca da Sexualidade em Aldeias Indígenas no Mato Grosso do Sul. Revista de Antropologia, v. 53, n. 1, 2010, p. 199-235.

CARNEIRO, Maria José. Ruralidade : novas identidades em construção. Estudos Sociedade e Agricultura, n. 11, 1988, p. 53-75.

2, n. 1, 2008, p. 9-38. . "Rural" como Categoria de Pensamento. Ruris, v.

CARRARA, Sérgio; SIMÕES, Júlio. Sexualidade, Cultura e Política: a trajetória da identidade homossexual masculina na antropologia brasileira. Cadernos Pagu, n. 28, 2007, p. 65-99.

CLIFFORD, James. A Experiência Etnográfica. Rio de Janeiro: EdUFRJ, 1998.

CLIFFORD, James; MARCUS, George. (orgs.). Writing Culture - 25th Anniversary Edition. Berkeley: University of California Press, 2010.

COSTA, Jurandir Freire. A Inocência e o Vício. Rio de Janeiro: RelumeDumará, 1992

FACCHINI, Regina. Movimento Homossexual no Brasil: recompondo um histórico. Cadernos AEL, v. 10, n. 18/19, 2003, p. 81-124.

FAUSTO-STERLING, Anne. Sexing the Body: gender politics and the construction of sexuality. Nova York: Basic Books, 2000. 
FEAL, Rosemary. Spanish American Ethnobiography and the Slave Narrative Tradition: "Biografía de un Cimarrón” y "Me Llamo Rigoberta Menchú". Modern Language Studies, v. 20, n. 1, 1990, p. 100-111.

FERNANDES, Estevão R. Homossexualidade Indígena no Brasil: desafios de uma pesquisa. Novos Debates, v. 1, n. 2, p. 26-33, 2014.

. Descolonizando Sexualidades: enquadramentos coloniais e homossexualidade indígena no Brasil e nos Estados Unidos. Tese de Doutorado, Estudos Comparados sobre as Américas, UnB, 2015.

FERREIRA, Paulo Rogers. Os Afectos Mal-Ditos: o indizível das sociedades camponesas. Dissertação de Mestrado, Antropologia Social, UnB, 2006.

. Os Afectos Mal-Ditos: o indizível das socie-

dades camponesas. São Paulo: Anpocs/Hucitec, 2008.

FOUCAULT, Michel. Deux Essais sur le Sujet et le Pouvoir. In: HUBERT, Dreyfus, RABINOW, Paul (orgs.). Michel Foucault, Un Parcours Philosophique. Paris: Gallimard, 1984, p. 297-321.

Janeiro: Graal, 1988.

. História da Sexualidade. 1: A Vontade de Saber. Rio de

FRY, Peter. Homossexualidade Masculina e Cultos Afro-Brasileiros. In: FRY, Peter. Para Inglês Ver: identidade e política na cultura brasileira. Rio de Janeiro: Zahar, 1982a, p. 54-86.

. Da hierarquia à Igualdade: a construção histórica da homossexualidade no Brasil. In: FRY, Peter. Para Inglês Ver: identidade e política na cultura brasileira. Rio de Janeiro: Zahar, 1982b, p. 87-115.

FRY, Peter; MacRAE, Edward. O Que é Homossexualidade. São Paulo: Brasiliense, 1983.

GONÇALVES, Marco Antônio et alii (org.). Etnobiografia - subjetivação e etnografia. Rio de Janeiro: 7 Letras, 2012.

GUIMARÃES, Carmen Dora. O Homossexual Visto por Entendidos. Rio de Janeiro: Garamond, 2004 [1977].

HARRIS, Mark. What it Means to be a Caboclo: some critical notes on the construction of Amazonian caboclo society as an anthropological object. Critique of Anthropology, v. 18, n. 1, 1998, p. 83-95.

HEILBORN, Maria. Luiza. Ser ou Estar Homossexual: dilemas de construção de identidade social. In: PARKER, Richard (org.). Sexualidades Brasileiras. Rio de Janeiro: Relume-Dumará, 1996.

Rio de Janeiro: Zahar, 1999.

. (org.) Sexualidades: o olhar das ciências sociais. 
neiro: Garamond, 2004 [1994].

Dois é Par: conjugalidade, gênero e identidade. Rio de JaHURTADO, Edson. Indígenas Homosexuales. La Paz: Conexión Fondo de Emancipación, 2014.

JAGOSE, Annamarie. Queer Theory - an introduction. NOVA York: New York University Press, 1996.

KEARNEY, Michael. Reconceptualizing the Peasantry; Anthropology in Global Perspective. Boulder: Westview Press, 1996.

KOFES, Suely. Uma Trajetória em Narrativas. Campinas: Mercado das Letras, 2001.

LANDES, Ruth. Matriarcado Cultual e Homossexualidade Masculina. In: $A$ Cidade das Mulheres. Rio de Janeiro: Civilização Brasileira, 1967.

LAURETIS, Teresa. A Tecnologia do Gênero. In: HOLLANDA, Heloísa (org.). Tendências e Impasses - O Feminismo como Crítica da Cultura. Rio de Janeiro: Rocco, 1994.

LEA, Vanessa R. O Som do Silêncio (Paul Simon). In: Cadernos Pagu, n. 41, 2013, p. 87-93.

LIMA-AYRES, Déborah M. A Construção História da Categoria Caboclo. Sobre Estruturas e Representações Sociais no Meio Rural. Novos Cadernos NAEA, v. 2, n. 2, 1999.

LOPES, Moisés. O Movimento LGBT da Baixada Cuiabana e a Segmentação de Identidades. In: Anais do III Simpósio Gênero e Políticas Públicas. Londrina: EdUEL, 2014.

McCALLUM, Cecilia. Nota sobre as Categorias "Gênero" e "Sexualidade" e os Povos Indígenas. In: Cadernos Pagu, n. 41, 2013, p. 53-61.

MARQUES, Roberto. Homoerotismo no Cariri Cearense: inscrições de um objeto em suas relações com o silêncio. Métis: história \& cultura, n. 10, 2012, p. 197217.

O Cariri e o Forró Eletrônico: percurso de uma pesquisa sobre festa, gênero e criação. Ponto Urbe, n. 15, 2014, p. 2-11.

MILLER, Darrel. Itá em 1974: um epílogo. In: WAGLEY, Charles. Uma Comunidade Amazônica. São Paulo: Editora Nacional, 1977 ( $2^{\mathrm{a}}$ edição).

MIRELLA, Luanna. Localidade ou Metrópole? Demonstrando a capacidade de atuação política das travestis no mundo-comunidade. Dissertação. (Mestrado em Antropologia). Brasília: PPGAS, 2010. 
MISKOLCI, Richard. A Teoria Queer e a Sociologia: o desafio de uma analítica da normalização. Sociologias, v. 11, n. 21, 2009, p. 150-182.

MOTT, Luiz. Dez Viados em Questão: tipologia dos homossexuais da Bahia. Salvador: Ed. Bleff, 1987a

ra, $1987 \mathrm{~b}$ . O Lesbianismo no Brasil. Porto Alegre: Mercado Aberto Edito-

MOTTA-MAUÉS, Maria Angélica. A Questão Étnica: índios, brancos, negros e caboclos. In: Estudos e Problemas Amazônicos. Belém: Idesp/Sedup, 1989, p. 196-204.

MOUTINHO, Laura. Diferenças e Desigualdades Negociadas: raça, sexualidade e gênero em produções acadêmicas recentes. Cadernos Pagu, n. 42, 2014, p. 201-248.

MUNIZ DE OLIVEIRA, J. Mulher com Mulher dá Jacaré": uma abordagem antropológica da homossexualidade feminina. Dissertação de Mestrado, Antropologia Social, UFRJ, 1992.

NASCIMENTO, Silvana de Souza. Faculdades Femininas e Saberes Rurais. Uma Etnografia sobre Gênero e Sociabilidade no Interior de Goiás. Tese de Doutorado, Ciência Social, USP, 2006.

. Homem com Homem, Mulher com

Mulher: paródias sertanejas no interior de Goiás. Cadernos Pagu, n. 39, 2012, p. 367-402.

universo trans na Paraíba. Revista de Antropologia, v. 57, n. 2, 2014, p. 377-411.

PARKER, Eugene (org.). The Amazon Caboclo - Historical and Contemporary Perspectives. Williamsburg: Studies in Third World Societies Publications, 1985 .

PARKER, Richard. Masculinity, Feminility, and Homosexuality: on the anthropological interpretation of the sexual meanings in Brazil. BLACKWOOD, Evelyn (org.). Anthropology and Homosexual Behavior. Nova Iorque: The Haworth Press, 1986.

PASSAMANI, Gustavo. Batalha de Confete e Outras Memórias: condutas homossexuais e curso de vida no carnaval do Pantanal. In: Anais da V Reunião Equatorial de Antropologia. Maceió: EdUFAL, 2015.

PENEFF, Jean. La Métode Biographique. Paris: Armand Collin, 1990.

PERLONGHER, Néstor. O Negócio do Michê: prostituição viril em São Paulo. São Paulo: Brasiliense, 1987. 
PISCITELLI, A. Interseccionalidades, Categorias de Articulação e Experiências de Migrantes Brasileiras. Sociedade e Cultura, v. 11, n. 2,2008, p. 263-274.

Interseccionalidades, Direitos Humanos e Vítimas. In: MISKOLCI, R., PELÚCIO, L. (orgs.). Discursos Fora da Ordem: sexualidades, saberes e direitos. São Paulo: Annablume; Fapesp, 2012, p. 199-226.

PIZARRO, Ana. Amazônia: as vozes do rio. Belo Horizonte: EdUFMG, 2012.

RICH, Adrienne. Compulsory Heterosexuality and Lesbian Experience. In: SNITOW, A.; STANSEL, C.; THOMPSON, S. (orgs.). Powers of Desire - The Politics of Sexuality. Nova York: Monthly Review Press, 1983, p. 177-205.

RODRIGUES, Carmen Izabel. Caboclo na Amazônia: a identidade na diferença. Novos Cadernos NAEA, v. 9, n. 1, 2006, pp. 119-130.

ROSALDO, Michelle. Zimbalist; LAMPHERE, Louise. (orgs.). A Mulher, a Cultura e a Sociedade. Rio de Janeiro: Paz e Terra, 1979.

SACCHI, Ângela e GRAMKOW, Márcia Maria (org.). Gênero e Povos Indígenas. Rio de Janeiro / Brasília: Museu do Índio e Funai, 2012.

SCOTT, Joan. Gênero : uma categoria útil de análise histórica. Educação e Realidade, v. 20, n. 2, 1995, p. 71-99.

. Experiência. In: SILVA, Alcione, LAGO, Mara Coelho de Souza e RAMOS, Tânia Regina Oliveira (orgs.). Falas de Gênero. Florianópolis: Editora Mulheres, 1999.

SIMÕES, Júlio \& Sérgio CARRARA. O Campo de Estudos Socioantropológico sobre Diversidade Sexual e de Gênero no Brasil: ensaio sobre sujeitos, temas e abordagens. Cadernos Pagu, n. 42, 2014, p. 75-98.

TOTA, Martinho. Eixos, Nexos e Câmbios de Diferença: discursos e trajetórias políticas envolvendo etnicidade, homossexualidade e religião. Bagoas, v. 7, n. 13, 2013, p. 295-322.

. Entre as diferenças: gênero, geração e sexualidades em contexto interétnico. Tese. (Doutorado em Antropologia Social). Rio de Janeiro: Universidade Federal do Rio de Janeiro, 2012.

TURNER, Victor, BRUNER, Edward M. (org.). The Anthropology of Experience. Urbana/Chicago: University of Illinois Press, 1986.

VANCE, Carole. A Antropologia Redescobre a Sexualidade. Physis, n. 5, 1995.

VIEIRA, Ricardo. Vidas Revividas: etnografia, biografias e a descoberta de novos sentidos. In: CARIA, T. (org.). Metodologias Etnográficas em Ciências Sociais. Porto: Afrontamento, 2003, p. 77-96. 
Identidades Pessoais: interacções, campos de possibilidade e metamorfoses. Lisboa: Colibri, 2009.

WAGLEY, Charles (org.). Man in the Amazon. Gainesville: University of Florida Press, 1974.

WOORTMANN, Ellen. Herdeiros, Parentes e Compadres. São Paulo: Hucitec, 1995 .

WOORTMANN, Ellen \& WOORTMANN, Klaas. Fuga a Três Vozes. Brasília: Anuário Antropológico/91; Rio de Janeiro: Ed. Tempo Brasileiro, 1993. 